\title{
TRUMP E A INFLEXÃO DA GRANDE ESTRATÉGIA
}

\author{
Williams Gonçalves ${ }^{1}$ \\ Tatiana Teixeira²
}

\begin{abstract}
Este trabalho se dedica a examinar se o governo Donald Trump tem sua política externa submetida a uma grande estratégia. Para tanto, inicialmente se discute o que é uma grande estratégia e em que esse conceito se distingue do de política externa. Ao mesmo tempo, explica-se a sua importância para a manutenção da hegemonia dos Estados Unidos ao longo da Guerra Fria. Neste sentido, argumenta-se que o consenso bipartidário em torno do objetivo estratégico foi fundamental para a elaboração e para o êxito final da grande estratégia. Em seguida, discute-se a dificuldade do exercício da hegemonia na ausência dessa estratégia, situação essa enfrentada pelos governos formados após a Guerra Fria. Por fim, debatem-se as ideias segundo as quais o governo Trump não dispõe de uma grande estratégia e o consenso bipartidário se dissolveu. 0 estudo busca mostrar que, embora o establishment norte-americano reconheça a irresistível ascensão da China à condição de grande potência rival, os formuladores de política internacional do país sentem bastante dificuldade em elaborar uma grande estratégia que assegure a hegemonia dos Estados Unidos e sua consequente capacidade de administrar a ordem internacional segundo seus interesses nacionais.
\end{abstract}

Palavras-chave: Estados Unidos; governo Donald Trump; grande estratégia; política externa; hegemonia; China.

\section{TRUMP AND THE INFLECTION OF THE GRAND STRATEGY}

This article examines if the foreign policy in Mr. Donald Trump administration is somehow subject to a grand strategy. For this purpose, we begin by discussing what a grand strategy is and how this concept differs from the one of foreign policy. At the same time, we explain the importance of the grand strategy for the endurance of U.S. hegemony throughout the Cold War. In this sense, we argue that the bipartisan consensus related to strategic means was crucial for the elaboration and final success of the grand strategy. Next, we discuss how hard it is the exercise of hegemony in the absence of a grand strategy. Actually, this was the situation face by post-Cold War governments. Finally, we debate if Mr. Trump's administration has or not a grand strategy. We also point to the dissolution of the bipartisan consensus. The U.S. establishment recognizes the irresistible rise of China as U.S. main rival. Still, despite it, U.S. foreign policy-makers have major difficulties to elaborate a grand strategy capable of ensuring U.S. hegemony and the capacity of managing an international order accordingly to its national interests.

Keywords: United States; Trump administration; grand strategy; foreign policy; hegemony; China.

1. Membro do Instituto Nacional de Ciência e Tecnologia para Estudos sobre os Estados Unidos (INCT-INEU); professor de relações internacionais na Universidade do Estado do Rio de Janeiro (UERJ); e professor no Programa de Pós-Graduação em Estudos Marítimos da Escola de Guerra Naval (PPGEM/EGN). E-mail:<williamsgon@terra.com.br>. 2. Pesquisadora no INCT-INEU; pesquisadora no Núcleo de Estudos e Análises Internacionais do Instituto de Políticas Públicas e Relações Internacionais da Universidade Estadual Paulista Júlio de Mesquita Filho (NEAI/IPPRI/Unesp); e editora no Observatório Político dos Estados Unidos (OPEU).E-mail:<tatianat19@hotmail.com>. 


\section{TRUMP Y LA INFLEXIÓN DE LA GRAN ESTRATEGIA}

Este artículo examina si la política externa del gobierno de Donald Trump responde a una gran estrategia. Para ello, discute inicialmente la definición de gran estrategia y en qué ese concepto se diferencia del de política externa. Paralelamente, explica la importancia de la gran estrategia en el mantenimiento de la hegemonía de Estados unidos a lo largo de la Guerra Fría. Argumenta, en ese sentido, que el consenso bipartidario sobre el objetivo estratégico fue esencial en la elaboración y el éxito final de la gran estrategia. Trata luego de la dificultad de ejercer la hegemonía en ausencia de una gran estrategia, una situación a la que se han visto confrontados los gobiernos posteriores a la Guerra Fría. Debate por último las ideas de que el gobierno de Trump carece de una gran estrategia y de que el consenso bipartidario se ha disuelto. El artículo busca demostrar que - pese a que el establishment estadounidense admita el irresistible ascenso de China como gran potencia rival - los formuladores de política internacional de Estados Unidos experimentan serias dificultades para elaborar una gran estrategia que asegure la hegemonía de Estados Unidos y su consiguiente capacidad de administrar el orden internacional en función de sus intereses nacionales.

Palabras clave: Estados Unidos; gobierno de Donald Trump; gran estrategia; política externa; hegemonía; China.

JEL: D72.

\section{INTRODUÇÃO}

As manifestações a respeito de temas internacionais e as decisóes tomadas pelo atual presidente norte-americano, Donald Trump, nesse âmbito, supostamente erráticas e sem nexo com os reais interesses nacionais do país e com a realidade da política internacional, têm suscitado a questão de seu governo ter ou não uma grande estratégia. Há momentos em que pronunciamentos e decisóes tomadas pelo republicano parecem ignorar o processo formal interagências, assim como orientaçóes de sua Comunidade de Inteligência, desalinhando-se com diretrizes dispostas em documentos oficiais, como a National Security Strategy (United States of America, 2017). Compóe-se, assim, um percurso que criaria distraçóes e confusão na comunidade política doméstica entre correligionários e nas expectativas de aliados, de países não tão aliados e de rivais.

Até o fato de o então conselheiro de Segurança Nacional, general Herbert Raymond McMaster, e o então secretário da Defesa, Jim Mattis, estarem no governo no momento da elaboração e da divulgação da National Security Strategy (United States of America, 2017) e da National Defense Strategy de $2018^{3}$ e, hoje, já terem deixado a administração aponta que ambos os documentos têm serventia limitada para entender a gestão Trump.

A falta de certeza sobre os Estados Unidos terem uma grande estratégia na verdade náo é nova, embora tenha ganhado mais vulto no governo Trump, em

3. Para sumário da National Defense Strategy de 2018, ver United States of America (2018). 
virtude, naturalmente, do seu estilo algo extravagante de governar e da eventual dissonância entre o discurso e a prática trumpista e anúncios de secretários, ou de outras autoridades da administração. As dúvidas a esse respeito já haviam começado a aparecer logo depois da Guerra Fria. Uma vez desfeita a estrutura bipolar do sistema internacional e o próprio Estado soviético tendo sido dissolvido, os Estados Unidos teriam caído em um vácuo estratégico, que teria se tornado de todo evidente no atual governo.

As aparentes imprevisibilidade e falta de racionalidade de Trump ofuscam, contudo, o que segue evoluindo como um governo coerente com a estratégia de America First e seu slogan Make America Great Again, propalados ao longo da campanha eleitoral de 2016 e reafirmados em seus principais pronunciamentos e tuítes na condição de presidente. Inspirada na plataforma isolacionista dos anos 1930, a America First renovada de Trump promete um país voltado para os interesses de sua população, e não para a defesa de um território distante qualquer, ou para a distribuição de ajuda humanitária de maneira indiscriminada, mas com um recorte político-ideológico afim; um governo preocupado com o fortalecimento da economia nacional (com o nível de protecionismo e de bilateralidade que forem necessários), e não com o compromisso de exportar a democracia como modelo de regime. Desde a corrida presidencial, quando ainda tinha um entendimento bem mais cru do que faria em sua política externa, Trump prometeu pragmatismo antes de tudo, inclusive nas relações com os históricos aliados transatlânticos.

A America First trumpiana é uma abordagem que busca rever (e reverter) os custos dos esforços de internacionalismo e de intervençôes militares e humanitárias mundo afora, assim como a adesão a tratados e a contribuição de Washington em segurança coletiva e em outras áreas, como finanças e comércio, direitos humanos e meio ambiente, em instituiçóes internacionais multilaterais como a Organização das Naçôes Unidas (ONU), a Organização Mundial do Comércio (OMC) ou a Organização do Tratado do Atlântico Norte (OTAN).

Onde os críticos veem contradiçẫo e inconsistência, Trump vê capacidade de negociação, autenticidade, ousadia, originalidade e - mais importante resultados positivos para os Estados Unidos. Além disso, o que muitos descrevem como a ausência de uma política externa sólida e harmoniosa poderia ser, como sugere Klare (2018), a "aderência" a um "conceito-chave estratégico" sobre o estabelecimento de um novo arranjo internacional: o de uma ordem tripolar, dividida entre Estados Unidos, China e Rússia. Essa acomodação não significaria, necessariamente, abrir mão de sua liderança, mas, sim, evitar conflitos e gastos supérfluos e enquadrar os "competidores".

Não parece haver discussóes oficiais e/ou a portas abertas em Washington para esse redesenho, nem sobre uma distribuição de áreas de influências. Publicamente, 
para a região da Eurásia, a diretriz vigente no establishment ainda seria a de conter e enfraquecer China e Rússia. Historicamente considerada pelos Estados Unidos como sua zona de influência direta, a América Latina é um elemento que não entra nesse tipo de cálculo, o qual tem sua lógica particular - inclusive em relação ao uso do tema dos direitos humanos - na visão norte-americana.

É o que se vê agora com a Venezuela, país para o qual a Doutrina Monroe tem sido abordada com cada vez mais frequência na fala de falcóes do governo norte-americano (especialmente o conselheiro de Segurança Nacional, John Bolton), junto com a prorrogaçáo do decreto de emergência nacional, que impóe sançôes a membros do governo Nicolás Maduro e restrições econômicas, além da defesa de um golpe institucional (ainda não se sabe se militar) dissimulado como "transição democrática".

Há, porém, indícios que se acumulam no governo Trump de que os Estados Unidos estariam contando, cada vez mais, com China e Rússia para avançar no tratamento de questóes internacionais, ao contrário de marginalizá-los política, econômica e estrategicamente. $\mathrm{O}$ objetivo seria tornar os custos dessas açóes os menores possíveis para os norte-americanos. Éo caso, por exemplo, das negociações com a Coreia do Norte de Kim Jong-un, nas quais a China deixou claro seu papel de "garante" de Pyongyang, ou da Síria, onde o presidente Vladimir Putin é um forte aliado de Damasco - no terreno e no Conselho de Segurança da ONU. Ao mesmo tempo, o chamado realismo de princípios trumpiano náo deixa de enviar navios para o mar do sul da China, cuja soberania é alvo de disputa por vários países da regiáo; ou, ainda, apoiar a Ucrânia, inclusive militarmente.

Esse projeto de um simulacro de nova ordem estaria há décadas em gestação por parte de Pequim e remontaria, acrescenta Klare (2018), à visita a Moscou do então presidente chinês, Jiang Zemin, para um encontro oficial com o ainda presidente Boris Yeltsin, em abril de 1997. Nele, ambos assinaram a Joint Declaration on a Multipolar World and the Establishment of a New International Order, na qual pedem um mundo multipolar e rejeitam a hegemonia global, mas sem se referirem diretamente aos Estados Unidos. "Nenhum país deveria buscar a hegemonia, praticar política de poder ou monopolizar os assuntos internacionais" (China..., 1997, tradução nossa), ${ }^{4}$ diz a declaração conjunta.

Com reverberação nos meios realistas clássicos, mas principalmente entre os institucionalistas liberais, uma avaliação que ocupa grande espaço no debate desde que Trump foi eleito é que o republicano estaria - de forma deliberada, ou como efeito de sua suposta falta de estratégia - acelerando a desconstrução dos

4. Todas as traduções são de responsabilidade dos autores. 
pilares da ordem internacional liberal criada pelos Estados Unidos e dotada de ganhos mútuos, regimes, instituições e parceiros conhecidos.

Em artigo na Foreign Affairs, Daalder e Lindsay (2018) chegam a sugerir a formação de um Grupo dos Nove (G9) para agir no lugar dos Estados Unidos. Em razão de seu produto interno bruto (PIB) e dos orçamentos de defesa, este grupo poderia ser composto por França, Alemanha, Itália, Reino Unido e União Europeia, assim como por Austrália, Japão, Coreia do Sul e Canadá. "Eles devem focar menos em como trabalhar com Washington e mais em como trabalhar sem ela" (Daalder e Lindsay, 2018, traduçáo nossa), aumentando os gastos em defesa e a cooperaçáo militar e econômica, de modo a conter os Estados Unidos e a China, manter as regras da ordem atual e oferecer a liderança, da qual os norte-americanos estariam abrindo mão.

Ao privilegiar o confronto à cooperação, o unilateralismo ao multilateralismo, a instabilidade à previsibilidade, a ameaça ao compromisso, Trump estaria pondo em risco, com essa disrupção, os valores da ordem pós-1945 e suas noções de segurança coletiva, democracia e livre mercado. Ele seria um agente desagregador, que, portanto, estaria desmontando a base de uma ordem que garantiu por décadas a proeminência dos Estados Unidos e a paz entre as principais potências mundiais, passando de uma "hegemonia liberal" para uma "hegemonia iliberal" (Posen, 2018).

Partindo-se dessas consideraçóes, após esta breve introdução, apresenta-se, na seçấo seguinte, a definição conceitual de grande estratégia considerada como base deste trabalho e, depois, na seção 3, discorre-se sobre suas transformaçōes na política externa norte-americana desde a Segunda Guerra Mundial. Em seguida, na seção 4, os autores analisam a ascensão e a consolidação da China como um contraponto à liderança global inequívoca dos Estados Unidos. Na seção 5, destacam-se algumas das principais decisóes do governo Trump em reaçáo a eventos internacionais ocorridos na primeira metade de seu mandato. Por fim, na seção 6, apresentam-se as consideraçóes finais. Espera-se, ao final, responder à pergunta que instigou os autores: teria Donald Trump uma grande estratégia? Em caso positivo, em que consistiria?

\section{DEFININDO A GRANDE ESTRATÉGIA}

A grande estratégia é uma das expressóes da inserção do Estado no sistema internacional. Ela é determinada pela densidade de poder do Estado e também pela maneira como ele é percebido pelos demais Estados integrantes do sistema. A elaboração de uma grande estratégia é prerrogativa reservada às grandes potências, mais precisamente àquelas que aspiram à posição hegemônica. Enquanto os demais atores estatais traduzem sua busca de realização dos interesses nacionais na formulação de política externa, as grandes potências exprimem sua vontade 
de poder na grande estratégia: o mais elevado e abstrato plano de condução dos negócios do Estado nas relaçóes que este mantém com os demais Estados.

Segundo Paul Kennedy (1991, p. 5, tradução nossa),

o ponto crucial da grande estratégia está, portanto, na política, ou seja, na capacidade dos líderes das naçôes de juntarem todos os elementos, tanto militares quanto náo militares, para a preservação e o avanço dos melhores interesses das naçôes no longo prazo (ou seja, em tempos de guerra e de paz). ${ }^{5}$

No caso das grandes potências, a política externa se submete à grande estratégia, funcionando como um dos instrumentos da luta pelo máximo poder, ao lado daqueles econômicos, políticos e militares. Já os demais Estados têm a política externa apenas como meio para sobreviver e alcançar objetivos mais imediatos. ${ }^{6}$

Para além dos cálculos estratégicos, que levam os Estados a otimizar esforços e a potencializar os recursos disponíveis com intuito antecipatório, trata-se de um quadro de referência intelectual flexível e necessariamente adaptável a variáveis de todo o tipo, composto de diretrizes e objetivos de médio e longo prazo (Brands e Porter, 2015). Quadro este que reflete e sintetiza uma visão de mundo responsável por acomodar demandas com diferentes interesses, especialmente no que diz respeito aos Estados Unidos e a seu sistema político repleto de atores relevantes para as tomadas de decisão. No caso dos Estados Unidos, lembram Brands e Porter (2015), ter uma grande estratégia ajudou a maior potência do mundo desde a Segunda Guerra a gerenciar capacidades e a "harmonizar poder e compromissos", enquanto moldava e ao mesmo tempo reagia a mudanças, de início, apenas conjunturais, mas, no decorrer do tempo, gradualmente sistêmicas.

\section{A GRANDE ESTRATÉGIA DOS ESTADOS UNIDOS EM PERSPECTIVA HISTÓRICA}

A Segunda Guerra Mundial representou um divisor de águas na história das relaçóes exteriores dos Estados Unidos. Em meio à guerra, o país passou da condição de grande potência à de aspirante à potência hegemônica. $\mathrm{O}$ ataque japonês à base naval de Pearl Harbor e a subsequente declaração de guerra dos

5. "The crux of grand strategy lies therefore in policy, that is, in the capacity of the nations' leaders to bring together all of the elements, both military and nonmilitary, for the preservation and enhancement of the nations' long-term (that is, in wartime and peacetime) best interests."

6. Edward N. Luttwak, em Estratégia: a lógica da guerra e da paz, assim define a grande estratégia: "Se recordarmos a imagem anterior da estratégia como um tipo de edifício de múltiplos níveis, com andares estabelecidos por ondas e contraondas de ação e reação, encontraremos que seu mais alto nível é muito mais espaçoso do que todos os outros mais baixos, de um modo que nenhuma arquitetura disponível permitiria. Para o nível da grande estratégia, as interações dos níveis militares mais baixos clamam resultados finais dentro do amplo contexto da política internacional, em interações adicionais com as relações não militares dos Estados: as trocas formais da diplomacia; as comunicações públicas da propaganda; as operaçỗes secretas; as percepções de outros, formadas pela Inteligência; e todas as transações econômicas do mais puro significado privado. Portanto, neste andar superior desproporcional, a rede resultante dos níveis técnicos, tático, operacional e da estratégia do teatro emerge numa contínua interação com todos aqueles relacionamentos entre Estados sempre afetados pelo que é feito, ou não, na esfera militar de um único Estado" (Luttwak, 2009, p. 265). 
alemães, determinando a entrada dos Estados Unidos na guerra que se iniciara na Ásia em 1937 e na Europa em 1939, deram início a um processo político interno que resultou em uma nova inserção deste país no sistema internacional e na formulação de uma grande estratégia.

A participação na guerra provocou o fim de uma antiga divisão e a formação de um novo consenso no establishment. A divisão que separava os membros da elite dirigente em isolacionistas e intervencionistas deu lugar a um consenso sobre a necessidade de os Estados Unidos assumirem a posição hegemônica. Sob a liderança de Franklin Roosevelt, a camada dirigente norte-americana se convenceu de que a Segunda Guerra Mundial aconteceu devido, em grande medida, ao fato de os Estados Unidos não terem assumido suas responsabilidades políticas internacionais ao fim da Primeira Guerra. Fazia-se necessário que essas responsabilidades fossem assumidas de uma vez por todas, para que outras guerras não viessem a acontecer.

Ainda antes de a guerra terminar, os norte-americanos já tinham assimilado a ideia de que os Estados Unidos eram mais importantes para o mundo do que o contrário. De acordo com o novo consenso unindo democratas e republicanos, a posição internacional a ser assumida pelo país era de fundamental importância para que a paz mundial fosse alcançada. Caso os norte-americanos se omitissem mais uma vez, o mundo correria o risco de permanecer enredado em guerras sem fim. A hegemonia dos Estados Unidos salvaria o mundo dessa ameaça e proporcionaria a paz para todos os Estados. ${ }^{7}$

O novo conceito sobre o papel a ser desempenhado pelos Estados Unidos no mundo que se inaugurava somente ganhou forma com a proposta da contençáo. Essa estratégia, originalmente formulada pelo diplomata George F. Kennan, caiu como uma luva na máo do presidente Harry Truman. Tornando-se conhecida como Doutrina Truman, a grande estratégia (da contenção) dos Estados Unidos objetivava "apoiar os povos livres que resistem às tentativas de subjugação por minorias armadas, ou por pressóes externas" (Gaddis, 2014, p. 256). Ainda que corrompesse o sentido original do longo telegrama, a interpretação que Truman deu ao conteúdo do relatório de Kennan correspondeu à urgência "de procurar doutrinas, ou fórmulas universais, com que vestir e justificar determinadas açôes" (op. cit., p. 257).

A execução do projeto hegemônico já havia se iniciado, na verdade, antes de a guerra chegar ao fim, em 1944, com as negociações de Bretton Woods, mediante

7. Philip Roth, em sua autobiografia, traduz muito bem o sentimento que a elite dirigente política instilou no conjunto da sociedade norte-americana ao fim da Segunda Guerra Mundial: "É difícil imaginar que qualquer pessoa inteligente que tenha crescido nos Estados Unidos depois da Guerra do Vietnã tenha tido a sensação inequívoca de pertencer à maior nação no mundo, que tivemos como jovens adolescentes logo depois da vitória sobre o fascismo nazista e o militarismo japonês" (Roth, 2016, p. 132). 
as quais os norte-americanos criaram a estrutura institucional da Nova Ordem Econômica Internacional. A resistência ainda apresentada por alguns setores da elite política norte-americana à ousadia do projeto liderado por Truman acabou, porém, vencida pelo influente apoio de Winston Churchill.

Em seu histórico discurso sobre a "cortina de ferro", na Universidade de Fulton, no Missouri, em 5 de março de 1946, o primeiro-ministro defendeu a necessidade de uma aliança militar-atômica da Grã-Bretanha com os Estados Unidos contra a ameaça à "civilização cristâ" representada pela União Soviética (Iakovlev, 1988, p. 54). Embora tivesse sido apeado do poder pelo eleitorado britânico ao fim do conflito mundial, substituído pelo líder trabalhista Clement Attlee, Churchill desfrutava de um grande prestígio pela liderança que exercera na luta contra o nazifascismo, e essa credibilidade foi usada por Truman para cimentar seu projeto hegemônico.

A interpretação do longo telegrama por Truman se tornou o fundamento da grande estratégia norte-americana ao longo de toda a Guerra Fria (Gaddis, 2006, p. 28). Com o passar do tempo, novas conjunturas foram se sucedendo, como o processo de descolonização e a formação do Movimento dos Países Não Alinhados. A contenção do comunismo se manteve, contudo, como núcleo da grande estratégia dos Estados Unidos até o colapso do mundo comunista no final dos anos 1980 .

O formidável desenvolvimento econômico, a liderança na pesquisa científica e na inovação tecnológica e o investimento na formação de sólido dispositivo militar-nuclear colocaram o país em uma posição bem acima das demais grandes potências do mundo ocidental. Sob sua hegemonia, estruturada na presença de suas grandes empresas, no controle das fontes de matérias-primas e de energia e em bases militares situadas em diversos pontos do mundo, as relaçôes entre as demais grandes potências foram pacificadas. Ao longo do período da Guerra Fria, houve guerras apenas entre países centrais contra países periféricos, ou entre países periféricos, mas não mais entre países do centro. Desse modo, por mais que a hegemonia causasse incômodos aos aliados em determinadas circunstâncias, os benefícios obtidos pela submissão ao poder dos Estados Unidos acabavam se revelando maiores do que os que se poderiam obter com a insubmissão (Kagan, 2003, p. 21).

A grande estratégia da contenção também produziu importantes mudanças na estrutura de poder e no relacionamento do Estado com a sociedade. Por ter persuadido o conjunto da sociedade de que o confronto nuclear com a Uniāo Soviética era uma possibilidade real, o Poder Executivo progressivamente absorveu mais poder em detrimento das prerrogativas do Congresso. A exigência de agilidade nas decisóes e o segredo nas informaçóes levaram ao fortalecimento político-institucional desse Poder. Ao mesmo tempo, essas exigências elevaram significativamente os gastos com 
segurança e defesa, resultando na estruturação de um complexo industrial-militar, que passou a se retroalimentar, com a complacência dos congressistas, muitos deles ligados direta e pessoalmente a esse complexo.

Os violentos protestos ocorridos no final da década de 1960, em decorrência dos efeitos internos da Guerra do Vietná, levaram a um questionamento da racionalidade do conflito no Sudeste Asiático por parte de determinados segmentos sociais, mas não foram suficientes para abalar essa estrutura, que se reforçou com a passagem do tempo. $\mathrm{O}$ argumento - segundo o qual os vultosos gastos militares e as guerras contínuas eram necessários para proteger a sociedade norte-americana e, assim, permitir que ela continuasse a gozar de seu elevado patamar socioeconômico permaneceu inalteravelmente vitorioso. Coube ao dispositivo cultural-informacional convencer a sociedade norte-americana de que o preço a pagar por uma vida próspera e livre do perigo comunista era investir permanentemente em armamentos e ter as Forças Armadas adestradas para intervir em qualquer parte do globo.

No início da década de 1990, verificou-se a grande mudança, a partir da qual os norte-americanos passaram a ver o seu país e o mundo de outra maneira. As reformas econômicas realizadas pelo governo chinês, a queda do Muro de Berlim, a dissolução do bloco soviético e a própria decomposição do Estado soviético foram episódios que encerraram a Guerra Fria, significando a completa vitória dos Estados Unidos. Essa vitória representou o fim de uma era e, ao mesmo tempo, um desafio de adaptação a um mundo novo, onde não havia mais inimigos.

A derrota eleitoral de George H. W. Bush (George Bush pai) para Bill Clinton em 1992 foi, como sublinha Cox (1995, p. 12), a mais clara evidência dessa mudança. O presidente que negociou o fim da União Soviética e que liderou a ampla coalizão que derrotou Saddam Hussein sofreu rejeição do povo norte-americano. A vitória eleitoral democrata mostrava que os êxitos em política externa já náo tinham mais tanta importância aos olhos do eleitorado. A nova tendência era de a sociedade se preocupar mais com as questóes domésticas e, sobretudo, com a situação da economia do país.

A nova percepção do eleitorado norte-americano, orientada no sentido de valorizar questóes mais imediatas e palpáveis como a situação da economia, não elidia, no entanto, preocupaçóes dos formuladores de política externa e de defesa. Para estes, grave questão se impunha: que novo papel os Estados Unidos desempenhariam no mundo? Como justificar a manutenção da posição hegemônica na ausência da ameaça comunista? Por qual razão deviam os aliados continuar a pagar o alto preço cobrado pelos Estados Unidos pela proteção que lhes davam, se a ameaça ao sistema deixará de existir?

Essas eram perguntas que remetiam a questôes de grande complexidade, relacionadas à autoimagem dos Estados Unidos e à sorte de importantes aliados 
situados em contextos regionais bastante intrincados. Destes, decerto o caso mais espinhoso se referia ao futuro da OTAN, que, aparentemente, perdia sua razão de ser. Por qual motivo os europeus continuariam a abrigar bases militares norte-americanas em seus territórios e a se submeter ao comando dos Estados Unidos? As mesmas perguntas valiam para os asiáticos.

É bem verdade que essas interrogações acabaram respondidas favoravelmente aos Estados Unidos. Não tanto pela capacidade de os norte-americanos apresentarem argumentos sólidos e persuasivos. Essas dúvidas foram superadas pelas necessidades dos próprios parceiros, que demandavam a presença norte-americana como forma de esconjurar seus problemas regionais. Na Europa, os aliados solicitaram a manutenção da OTAN, preocupados com o surgimento de uma política externa e de defesa alemã independente. Para os europeus, a retirada norte-americana do continente poderia abrir espaço para a expansão dos nacionalismos, particularmente o temido nacionalismo alemão. Suprimido o fantasma da expansão soviética, a permanência dos Estados Unidos na Europa servia para sofrear suas históricas contradiçôes. Já na Ásia o problema era a China, com os aliados da regiâo solicitando a manutenção dessas estruturas de poder por temerem o seu progressivo fortalecimento.

Em momento algum os formuladores norte-americanos cogitaram romper essas alianças, mas sabiam que a dinâmica das relaçóes internacionais acabaria por impor mudanças nos dados e nas percepçóes. O que parecia um grande problema naquele contexto podia se esvaziar com o tempo, revelando prescindível a preocupação com o apoio dos Estados Unidos. Por isso, fazia-se necessária uma grande estratégia com a força aglutinadora semelhante àquela da contenção. Não bastava defender os interesses nacionais e parecer fiel aos aliados. Era fundamental que a presença norte-americana estivesse lastreada em uma doutrina que justificasse os custos políticos e econômicos dessa presença.

A tese sedutora e triunfalista de "fim da história" não resistiria por muito tempo. Como diversos estudiosos do país vaticinavam, a unipolaridade advinda do colapso do mundo comunista seria passageira (Kupchan, 2012). A hegemonia norte-americana seria desafiada por alguma potência que, ao acumular poder e ascender na hierarquia dos Estados, manifestaria seu desconforto com a ordem internacional e assumiria o desafio de criar uma nova ordem. Hoje, sete mandatos presidenciais depois da Guerra Fria, duas coisas podem ser constatadas quanto à formulação de uma grande estratégia que substituísse com a mesma eficácia a estratégia da contenção.

A primeira é que os teóricos que proclamaram que a situação de unipolaridade desfrutada pelos Estados Unidos era transitória estavam com a razão (Brzezinski, 2013; Layne, 1997). A partir dos anos 2000, a estrutura do sistema internacional sofreu profundas alteraçóes, fazendo com que a definição mais adequada de sua 
estrutura fosse de multipolaridade. Em virtude dos senóes que tal multipolaridade apresenta em relação ao seu tipo ideal, ${ }^{8}$ a conceituação que melhor corresponde à realidade é aquela proposta por Mearsheimer (2001, p. 45): a de uma estrutura multipolar desbalanceada, ou uma multipolaridade que comporta grande diferencial de poder entre as potências.

A estratégia de "balanceamento externo" (offshore balancing) traria melhores resultados para os Estados Unidos, ao "preservar o domínio americano no hemisfério ocidental e conter potenciais hegemons na Europa, no Nordeste Asiático e no Golfo Pérsico", ao "estimular outros países a assumir a liderança no monitoramento de potências emergentes", ou ainda ao "manter os Estados Unidos tão poderosos quanto possível (...), mantendo a hegemonia no hemisfério ocidental" (Mearsheimer e Walt, 2016, tradução nossa). No caso das duas primeiras regióes citadas, afirmam os autores, "o objetivo principal (...) deveria ser manter o equilíbrio regional de poder”, uma equação que envolveria Rússia e China, respectivamente. Ainda segundo Mearsheimer e Walt (op. cit.), com essa grande estratégia realista, os Estados Unidos teriam condiçóes de regular seu efetivo militar de acordo com a distribuição de poder nessas três regióes, reduzindo gastos para a defesa e investindo esses recursos em casa.

O segundo ponto a ser constatado é que em nenhum governo dos quatro presidentes que exerceram os sete mandatos no período posterior à Guerra Fria George H. W. Bush (um mandato), Bill Clinton (dois mandatos), George W. Bush (dois mandatos) e Barack Obama (dois mandatos) - houve uma formulação política que possa ser considerada uma grande estratégia. Todos buscaram o mesmo objetivo de apresentar uma justificativa duradoura para o exercício da hegemonia norte-americana, mas não obtiveram sucesso. A orientação teórica da política externa do governo de cada um deles se esgotou na mesma medida de seus mandatos e das ameaças conjunturais exógenas.

Sob o forte impacto do fim da Guerra Fria, George Bush pai anunciou o advento de uma Nova Ordem Mundial. Ordem essa que nunca se materializou e tampouco chegou a ser definida por seu governo. Fragilizado pela recessão econômica, Bush foi derrotado eleitoralmente por Bill Clinton ao tentar a reeleiçẫo em 1992. Uma vez superada a bipolaridade, o democrata proclamou a responsabilidade dos Estados Unidos diante do restante do mundo de guiá-lo na nova época que se abria com seu governo - a época da globalização (Posen e Ross, 1997) -, mediante a execução de uma política externa e de segurança nacional

8. 0 tipo ideal de estrutura multipolar de sistema internacional é o europeu do século XIX, em que cinco potências Inglaterra, França, Rússia, Prússia e Império Austríaco - negociavam as mudanças no continente. 
de envolvimento e expansão dedicada às questôes comerciais, à consolidação do liberalismo e à promoção da democracia mundo afora. ${ }^{9}$

Buscando conciliar interesse e legitimidade, coerção e persuasão, em um contexto internacional mais interdependente e de certeza da liderança norte-americana (Guimarães, 2000), a Revisão Quadrienal de Defesa da época alertava para o surgimento de peer competidors, em uma referência à China e à Rússia. Embora seu governo tenha conseguido universalizar a ideologia da globalização, ao conquistar a adesão da mídia e da academia, enfrentou forte oposiçấo nacionalista internamente.

George W. Bush assumiu a presidência afirmando a condição de crítico da ideologia da globalização e interpretando-a como nociva aos interesses nacionais. Logo após ter seu governo sacudido pelo impacto do ataque terrorista às Torres Gêmeas e ao Pentágono, declarou seu compromisso de priorizar a Guerra Global ao Terror. Guiou-se pelo unilateralismo e recorreu ao medo como fator de coesão social interna para levar adiante sua política de fortalecimento do poder de Estado, assim como recorreu ao investimento em recursos para aumentar a projeção de poder (Guimarães, 2002; 2007; 2008). Desdenhou da persuasão, preferindo a imposição dura do poder, o que se traduziu em rejeição aos acordos e às instituições multilaterais. Aqui, a China é definida como um concorrente estratégico, a Rússia é vista com preocupação e acordos e instituiçôes multilaterais são rejeitados ou ignorados.

Sem abrir mão de continuar combatendo o terrorismo, Barack Obama anunciou uma nova ênfase no multilateralismo, por meio do qual os Estados Unidos promoveriam a paz no mundo, renovando o smart power, ou poder inteligente, estabelecendo alianças pragmáticas e transformando inimigos em amigos ou parceiros. Manter e reforçar a ordem internacional instituída, sob a "indispensável” liderança norte-americana, constituía os alicerces dessa estratégia.

Temos uma oportunidade - e obrigaçáo - de liderar o caminho, reforçando, moldando e, quando apropriado, criando regras, normas e instituiçóes que sáo a base para a paz, segurança, prosperidade e proteção dos direitos humanos no século XXI. O sistema internacional dos dias atuais depende fortemente de uma arquitetura internacional legal e de instituiçóes políticas e econômicas, assim como de alianças e parcerias dos Estados Unidos e de outras naçóes afins estabelecidas depois da Segunda Guerra Mundial. Apoiado por uma robusta liderança americana, este sistema nos serviu bem por setenta anos, facilitando a cooperaçáo internacional,

9. Robert B. Reich, um dos mais influentes conselheiros de Bill Clinton, teórico da globalização, argumentava que, com o fim da Guerra Fria, a geopolítica fora substituída pela geoeconomia. "A questão fundamental para os Estados Unidos no mundo pós-União Soviética - um Estados Unidos diferente, cuja economia e cultura estão fundindo-se rapidamente às economias e culturas do resto do globo - é se haverá a possibilidade de redescobrir nossa identidade e nossa responsabilidade mútua, sem ter de criar um novo inimigo. A resposta é extremamente duvidosa" (Reich, 1994, p. 304). 
a divisão de responsabilidades e a prestação de contas (United States of America, 2015, p. 23, tradução nossa). ${ }^{10}$

As evidentes diferenças de orientação de política externa dos governos pós-Guerra Fria não escondem um elemento comum a todas: a ideia bipartidariamente consensual da hegemonia dos Estados Unidos. Havia discordância quanto à grande estratégia mais adequada que manteria a hierarquia internacional sob a liderança dos Estados Unidos, mas não havia discordância quanto à necessidade de manutenção dessa hierarquia e dessa liderança. No decorrer dos anos 1990, essa ideia não foi contestada, pois a hegemonia foi por todos, dentro e fora do país, interpretada como uma consequência natural do colapso do mundo comunista e da Uniấo Soviética.

A assim chamada unipolaridade levou a crer, sob o embalo do conceito de globalização, que a geopolítica tinha dado lugar à geoeconomia e que, doravante, as questôes a dividir os Estados seriam pacificamente resolvidas pelas leis do mercado. No entanto, a reação nacionalista da Rússia à geral degradação ocorrida sob a orientação das instituiçóes econômico-financeiras internacionais e a irresistível ascensão econômica da China, impulsionada por sua completa integração à globalização econômica, mudaram significativamente o quadro internacional, comprometendo muito claramente a ideia de unipolaridade e de natural hegemonia dos Estados Unidos no sistema internacional.

Reconhecendo as significativas mudanças no sistema internacional, Richard Haass, então presidente do Council on Foreign Relations, afirmava, em 2008, que o sistema tinha deixado de ser unipolar, tendo se tornado náo polar - "o mundo de hoje é dominado não por um ou dois, ou mesmo por vários Estados, mas, sim, influenciado por dúzias de atores estatais e não estatais, exercendo vários tipos de poder. Isso representa uma mudança tectônica em relaçáo ao passado" (Haass, 2008, p. 1, tradução nossa). ${ }^{11}$

O comportamento reverente dos demais Estados ante a liderança dos Estados Unidos começou a dar lugar a um comportamento mais crítico a partir da reação militarista unilateral do governo George W. Bush aos atentados do 11 de Setembro. O desdém para com os mecanismos multilaterais, junto com a disposição de apelar para o uso da força para impor sua vontade, corroeu o prestígio que havia marcado a ação internacional na década anterior. Se, de um

10. "We have an opportunity - and obligation - to lead the way in reinforcing, shaping, and where appropriate, creating the rules, norms, and institutions that are the foundation for peace, security, prosperity, and the protection of human rights in the 21st century. The modern-day international system currently relies heavily on an international legal architecture, economic and political institutions, as well as alliances and partnerships the United States and other like-minded nations established after World War II. Sustained by robust American leadership, this system has served us well for 70 years, facilitating international cooperation, burden sharing, and accountability."

11. "(...) a world dominated not by one or two even several States but rather by dozen so factors possessing and exercising various kinds of power. This represents a tectonic shift from the past." 
lado, o ataque militar ao Afeganistão foi apoiado por todos como legítima reação ao ataque terrorista, de outro, a invasão do Iraque, em 2003, foi considerada desnecessária e abusiva pelos aliados e teve como consequência crescente um generalizado sentimento antinorte-americano.

A essa perda de prestígio somou-se uma grave crise econômica, a partir de 2008. Uma crise que envolveu e enfraqueceu a economia dos parceiros europeus, no momento em que a economia chinesa percorria o caminho inverso, crescendo significativamente e levando a reboque outras economias do mundo em desenvolvimento. Além disso, para evitar efeitos econômicos ainda mais danosos da crise, o governo George W. Bush se viu na necessidade de abandonar os pressupostos ultraliberais que haviam marcado sua ação e adotar, a contragosto, uma forte intervenção do Estado na economia, para salvar bancos e impedir, assim, o travamento do sistema de crédito.

O governo Obama iniciou prometendo ser a antítese de seu predecessor. Para isso, deveria buscar soluçóes para os dois grandes problemas deixados por Bush: a crise econômica e suas sequelas sociais, além da perda de prestígio dos Estados Unidos no mundo. Na frente externa, o êxito de seu programa dependia de como conseguiria enfrentar as questóes que demandavam respostas mais urgentes: a retirada das tropas do Afeganistáo e do Iraque, a recuperação da capacidade de exercer liderança nos foros multilaterais, a redução do arsenal nuclear, que supunha diálogo e acordo com a Rússia, e o estabelecimento de um diálogo e talvez uma parceria com a China.

Ainda que mantivesse o compromisso de combatero terrorismo internacional, cujo alvo principal era Osama bin Laden, considerado o responsável pelos ataques do 11 de Setembro, Obama priorizava investir no diálogo e na cooperação para recuperar a liderança dos Estados Unidos. Tão enfaticamente se mostrou propenso a executar esse programa que a ele foi conferido o Prêmio Nobel da Paz, apenas nove meses após a posse.

Há, porém, uma diferença importante entre a promessa de Obama e a de George W. Bush. Ela se refere à divergência dos governos quanto aos meios, ainda que ambos tenham convergido quanto ao fundamental: o propósito de afirmar o papel essencial dos Estados Unidos como referência para a manutenção da ordem internacional liberal que havia se estruturado ao fim da Segunda Guerra Mundial. Embora divergindo quanto à melhor política para continuar a desempenhar esse papel, Obama e Bush se mantiveram fiéis ao consenso bipartidário, segundo o qual compete aos Estados Unidos zelar pela ordem internacional.

Em face dessa questão, apresenta-se o argumento central desta análise da grande estratégia dos Estados Unidos: há, no governo Trump, uma ruptura nesse sentido, na medida em que este diferencia-se dos seus antecessores por romper 
o consenso bipartidário e alterar a inserção do Estado no sistema internacional. $\mathrm{Na}$ nova inserção internacional dos Estados Unidos, não há mais lugar para a elaboração de uma grande estratégia nos moldes tradicionais.

O governo Trump tem inaugurado uma nova fase, na qual os Estados Unidos continuam se comportando e sendo reconhecidos como grande potência, uma vez que não perderam o poderio econômico, e tampouco tiveram enfraquecido seu dispositivo militar-nuclear. Em virtude das mudanças no sistema internacional, porém, não conseguem mais exercer o antigo papel de potência hegemônica. Embora seus recursos de poder sejam muito elevados, as condiçóes gerais não permitem mais que a imposição de seus interesses seja percebida como algo natural e necessário pelos demais Estados. Como dirá Bacevich (2017, tradução nossa), "a resposta da America First para as mudanças em curso na ordem internacional deveria começar com o reconhecimento de que o momento unipolar passou. A nossa era é multipolar".

Para desenvolver esse argumento, antes de analisar o desempenho do governo Trump, faz-se indispensável apontar aquelas mudanças ocorridas no sistema internacional que concorreram decisivamente para a redução do poder relativo dos Estados Unidos. Não há dúvida de que as mais importantes foram a irrupção da China na condição de grande potência econômica, o esforço empreendido pela Rússia para recuperar sua condição de grande potência e a formação do BRICS (acrônimo formado por Brasil, Rússia, Índia, China e África do Sul), uma busca de inserção internacional por meio de alianças estratégicas. A percepção do governo Trump do impacto desses fatores combinados explica em grande medida sua política externa.

Diante desse contexto internacional, na prática, a política antiglobalização de Trump se traduz na tentativa de conter a marcha ascendente chinesa no caminho da hegemonia mundial, pois a China se constitui como a principal potência oponente. Acomodar a Rússia seria uma parte dessa política, que também se traduziria em abandonar projetos por ele considerados muito dispendiosos e que comprometem as condiçóes de vida de segmentos sociais, com os quais se acha comprometido.

\section{AS TRANSFORMAÇÕES INTERNACIONAIS}

\subsection{A irrupção da China}

O crescimento da China teve início com as reformas introduzidas por Deng Xiaoping em 1978, conhecidas como as Quatro Modernizaçōes - indústria, agricultura, ciência e tecnologia e Forças Armadas. Essas reformas sinalizavam a vitória da corrente produtivista sobre a corrente liderada por Mao Zedong. Os resultados das reformas apareceram em tempo breve. Com a abertura das 
Zonas Econômicas Especiais (ZEEs) - Shenzhen, Zhuhai, Shantou e Xiamen - e de seu mercado para os investimentos estrangeiros, a economia chinesa passou a apresentar índices de crescimento na casa dos dois dígitos (Marti, 2007, p. 9). Até 2010, o PIB chinês cresceu a uma média anual de 10\%, passando, a partir de então, a crescer com taxas mais moderadas, da ordem de $7 \%$ ao ano. Mediante uma agressiva política de exportação de produtos de baixo custo, ao alcance do orçamento de consumidores de baixa renda, a China se tornou uma parte importante da economia internacional.

Essa importância aumentou consideravelmente quando o governo chinês aceitou o desafio da globalização e passou a importar grandes quantidades de produtos alimentícios e de petróleo. Ao abrir mão da autossuficiência que mantivera desde a Revolução de 1949, a China ingressava em um novo momento. Nessa etapa, iniciada em meados dos anos 1990, o país se tornou um dos promotores da globalização. Isso se efetuou na forma de exportação de produtos de mais alto valor tecnológico agregado para mercados de consumidores de renda mais alta, bem como na forma de maior articulaçáo política junto a países em que investia capitais e com os quais realizava importaçóes importantes para o funcionamento de sua economia.

As colossais exportaçôes e importaçóes que realizava foram responsáveis pelo crescimento de numerosos países da América Latina e da África, numa fase em que as economias desenvolvidas tentavam se recuperar da crise de 2008. Por realizar negócios sem se envolver nas questóes políticas internas dos parceiros, os chineses conseguiram invadir áreas até então de influência de europeus e de norte-americanos, que têm procurado reagir a essa invasão de diversas maneiras.

Ao crescimento econômico correspondeu um maior engajamento da China nas organizaçôes que formam a ordem internacional. Segundo Zhongqi (2010, p. 48), o engajamento chinês evoluiu em três estágios. O primeiro se deu com a participação em organizaçôes pertinentes à autodeterminação e à preservação da soberania nacional. O segundo aconteceu com a adesão ao Banco Asiático de Desenvolvimento (BAD) e ao Acordo Geral sobre Tarifas e Comércio (General Agreement on Tariffs and Trade-GATT), em 1986. O terceiro estágio verificou-se a partir de meados dos anos 1990, quando a China passou a integrar a maioria das organizaçóes internacionais, especialmente as multilaterais, com destaque para a participação na OMC e a criação da Organização para Cooperação de Xangai, ambas em 2001.

A passagem para o segundo estágio do envolvimento da China na ordem internacional, que implicou a internalização das regras específicas impostas por cada uma dessas instituiçóes, correspondeu ao completo enredamento no processo de globalizaçáo. O vigoroso crescimento econômico e os vultosos 
investimentos em infraestrutura acarretaram uma significativa ampliação das relaçóes econômicas da China com todos os países do mundo.

Não é de se estranhar, portanto, que os Estados Unidos tenham começado a reagir a esse crescimento econômico e a essa rede de elos políticos que os chineses criaram ao redor do mundo. $\mathrm{O}$ incômodo com a expansão chinesa já se manifestara no governo Obama, que passou a considerar a Ásia como "pivô", uma área estrategicamente mais sensível para os Estados Unidos. O tom era mais cauteloso, porém, do que no do governo que lhe sucedeu.

\subsection{A reabilitação da Rússia}

A reabilitação da Rússia como potência mundial aconteceu com a eleição de Vladimir Putin, em 2000. Nos anos 1990, a Rússia atravessou uma séria crise. O processo conduzido por Boris Yeltsin de transformar a economia centralmente planificada em economia de mercado foi bastante acidentado. Além das dificuldades de converter o sistema político antes existente em sistema político democrático de perfil ocidental, as grandes empresas russas caíram nas mãos de oligarquias com bastante liberdade de atuaçáo. A chegada de Putin à Presidência, inicialmente substituindo Yeltsin de forma provisória e, depois, como presidente eleito, mudou essa situação. Beneficiado pela alta dos preços do petróleo e do gás e limitando a liberdade das oligarquias econômicas, mediante o exercício da autoridade das instituiçóes de Estado, Putin pacificou a sociedade russa, ao mesmo tempo que promoveu o crescimento econômico.

O bom desempenho da economia aproximou a Rússia do Ocidente. Tal aproximaçáo teve como ponto alto o convite para a Rússia integrar o Grupo dos Sete (G7), que reúne as mais desenvolvidas economias industriais do mundo. A boa relação com o Ocidente, no entanto, teve curta duração, uma vez que Putin revelou não estar disposto a negociar posiçóes caras ao nacionalismo russo. Por considerar que a OTAN praticava uma política de cooptação de países da Europa Oriental com a nítida intenção de isolar Moscou e impedir que esta voltasse a se expandir por aquela área e reconstituísse seu antigo império, ou mesmo a área da ex-Uniáo Soviética, Putin passou a hostilizar abertamente o Ocidente e a denunciar a globalização como um instrumento de dominação ideológica ocidental.

\subsection{A criação do BRICS}

O BRICS foi criado em 2006 como uma articulaçáo político-diplomática. Em 2009, assumiu-se como grupo político. Reunindo, inicialmente, Brasil, Rússia, Índia e China e, posteriormente, agregando a África do Sul, o BRICS nasceu com o compromisso de atuar no sentido de promover uma nova ordem internacional. 
Favorecidos por um significativo crescimento econômico, em grande medida alavancado pelo crescimento chinês, esses grandes países da periferia, unidos à Rússia, que empreendia sua reabilitação como grande potência, passaram a ter destacada atuação internacional. Ao interagirem mais intimamente, os integrantes do BRICS foram descobrindo possibilidades novas de entrosamento entre eles e aumentando o volume de comércio, bem como foram elevando o grau de cooperação nos planos de educação, cultura e ciência e tecnologia.

A ação mais contundente do BRICS se deu com a criação, em 2012, do Arranjo Contingente de Reservas (ACR) e do Novo Banco de Desenvolvimento (NDB). Com a finalidade de apoiar o processo de desenvolvimento econômico-social dos países da periferia na área de construção de infraestrutura, essas duas instituiçóes se apresentam como alternativas ao Fundo Monetário Internacional (FMI) e ao Banco Mundial, que sempre estiveram voltados para a sustentação dos interesses dos países desenvolvidos desde sua criação em 1944, em Bretton Woods.

A ordem internacional de Bretton Woods vem sendo criticada desde os anos 1970, quando o então denominado Terceiro Mundo lançou a ideia de uma Nova Ordem Econômica Internacional, que mobilizou as lideranças políticas - sobretudo aquelas vinculadas ao Movimento dos Países Não Alinhados. Diferentemente desse movimento dos anos 1970, o BRICS se constitui como uma ameaça real aos interesses dos Estados Unidos e de seus aliados do G7. Envolve poucos grandes países, que são líderes regionais, o que facilita significativamente o trabalho de articulação política, como bem demonstram os encontros anuais de seus líderes, e também reúne potências nucleares (Rússia, China e Índia). Duas destas - Rússia e China - têm assento permanente no Conselho de Segurança da ONU.

\section{O GOVERNO TRUMP}

Na base da rejeição do governo Trump a grandes acordos comerciais e a instituiçóes internacionais estaria o populismo jacksoniano, nacionalista e individualista, historicamente associado ao homem branco, protestante, das classes baixas e médias, com formação abaixo da média nacional, que ficou sem emprego ou que se vê ameaçado de perdê-lo (Mead, 2000; 2017). É aquele que se considera ameaçado pela diversidade racial e cultural, desconfia das elites, do livre comércio, da imigração e dos compromissos externos, rejeita o globalismo e é um ferrenho defensor da soberania e do poder americanos.

Assim como Andrew Jackson, afirma Walter Russell Mead (Glasser, 2018; Mead, 2016), a política externa de Trump é menos inflamada do que sua retórica, e as guerras, vistas como um último recurso - salvo se a América for atacada. Para a política externa vale a mesma orientação que a da política doméstica: "O governo deveria fazer tudo o que está em seu poder para promover 
o bem-estar - político, moral, econômico - de sua comunidade" (Mead, 2000, tradução nossa). ${ }^{12}$ Em suas origens, o movimento America First teria justamente esse objetivo: "garantir a segurança e o bem-estar dos Estados Unidos sem se envolver em guerras desnecessárias” (Bacevich, 2017, tradução nossa). ${ }^{13}$

Diferentemente de wilsonianos (defensores dos princípios morais), hamiltonianos (realistas) e jeffersonianos (pregadores dos ideais democráticos), para os jacksonianos é preciso haver uma ameaça clara e concreta ao interesse nacional, já que alegaçôes de ordem moral não são suficientes para mobilizar o apoio desse grupo. Também ao contrário do que se viu com os neoconservadores do governo George W. Bush, não se trata de investir em nation-building ou de ser um modelo, o "farol" para o mundo. O eleitorado de Trump espera menos multilateralismo e menos intervencionismo. Guerras não devem ser usadas como elemento de distração de imbróglios domésticos, mas, uma vez que se decida entrar em um conflito, deve-se ir até o fim. Jacksonianos não são dados a hesitaçóes nesse plano.

Confrontar a Coreia do Norte, manter tropas na Síria e no Afeganistão, alargar a OTAN, incluindo países da parte leste da Europa limítrofes da Rússia, e pressionar a Rússia de modo a isolá-la completamente sáo políticas que Trump considera dispendiosas e que somente atendem aos interesses do complexo industrial-militar. Este comporta aquilo que Mead (2000) chama de lobby de guerra norte-americano, o qual costuma ser acionado em momentos de crise nacional:

uma força política que, sob certas circunstâncias, pede a guerra, apoia o uso decisivo da força e pede aos líderes políticos que parem de perder tempo com negociaçôes, sançóes e encontros no Conselho de Segurança, de modo a atacar o inimigo com toda força possível (Mead, 2000, tradução nossa).

Trump se elegeu presidente assegurando a seu eleitorado que reverteria todas as decisóes de seu antecessor. Tanto na cena doméstica quanto na externa, o início da atual gestáo foi marcado pela obsessão com a adoçáo de políticas anti-Obama e pela preocupação com questóes de segurança, ainda em função da atuação do Estado Islâmico (EI) no Oriente Médio e dos diversos ataques cometidos em nome do grupo em países aliados - sobretudo na Europa.

Após mais de dois anos de mandato, o republicano segue firme no processo de desmantelamento das políticas do democrata, com as notórias saídas, no plano externo, do Acordo de Paris sobre o clima, do acordo nuclear entre o Irã e o P5+1 (o Joint Comprehensive Plan of Action - JCPOA), país ao qual impôs

12. "The government should do everything in its power to promote the well-being - political, moral, economic - of the folk community."

13. "(...) to ensure the safety and well-being of the United States without engaging in needless wars." 
novas sanções, do Acordo de Parceria Transpacífica (Trans-Pacific Partnership Agreement-TPP), do Conselho de Direitos Humanos e da Organização das Naçóes Unidas para a Educação, a Ciência e a Cultura (Unesco), ambos da ONU - ou, mais recentemente, com a substituição do Acordo de Livre Comércio da América do Norte (North American Free Trade Agreement - NAFTA) pelo Acordo Estados Unidos-México-Canadá (United States-Mexico-Canada Agreement - USMCA).

É possível distinguir dois momentos no governo Trump, com a elevada dança das cadeiras no alto escalâo sendo um bom indicativo desse vaivém nos anúncios e na tomada de decisão do presidente. Lembre-se de que é grande e incomum, para um período tão curto em um mandato, o número de baixas entre demissões e deserçóes - registradas na primeira metade do governo Trump.

Até agora, restringindo-nos apenas aos principais cargos e que se relacionam mais diretamente com o assunto desenvolvido neste trabalho, já são dois secretários de Estado (Rex Tillerson e Mike Pompeo), um de Defesa (Jim Mattis), dois de Segurança Interna (John Kelly e Kirstjen Nielsen) e três conselheiros de Segurança Nacional (Michael Flynn, general Herbert Raymond McMaster e John Bolton), além da saída de assessores influentes como o estrategista de extrema direita Stephen (Steve) Bannon (Lu e Yourish, 2019). Estes números incluem o ocupante atual do respectivo cargo, mas não os interinos.

Ao tomar posse, o presidente recém-eleito ainda tem de administrar a agenda passada, mas precisa, igualmente, marcar posiçóes que estabeleçam sua identidade e que justifiquem para sua base eleitoral sua chegada ao poder. Assim, no primeiro momento, Posen (2018, tradução nossa) aponta que o governo republicano se manteve "comprometido com a competição geopolítica com as maiores potências militares do mundo e com as alianças formais e informais que ele herdou", "ameaçou com novas guerras", "continuou guerras em curso contra os talibãs no Afeganistão e contra o EI no Iraque e na Síria, com mais recursos e com mais violência do que seus antecessores", e "anunciou planos para investir ainda mais dinheiro no Departamento da Defesa”.

Em um episódio que destoa do padrão apontado neste trabalho e que foi considerado uma espécie de concessão aos conservadores tradicionais do Partido Republicano e de distinção com a política de Obama, encaixando-se nesse primeiro momento, Trump atacou a base aérea Shayrat, em Homs, na Síria, em 2017. À época, alegou que Bashar al-Assad teria ultrapassado a "linha vermelha", ao usar armas químicas contra sua população. Também nesse início de governo, seguiu com mais frequência o roteiro formal de tomadas de decisão por meio da consulta interagências e entre departamentos, ainda permanecendo no NAFTA e sem romper o acordo com o Irã (Wright, 2019). Isso mudaria mais adiante, incluindo o anúncio de retaliaçóes aos países que negociarem com Teerã. 
Na segunda fase de sua política externa, mais dura e mais unilateralista, Trump busca mais autonomia decisória, ignorando muitas das orientaçóes derivadas do processo interagências (Wright, 2019). Envolveu-se em uma longa e cara disputa comercial com a China, ainda em aberto em 2019, e decidiu, aparentemente sem amplas consultas prévias, reunir-se com o líder norte-coreano. Duas cúpulas já foram realizadas (Singapura, em 2018, e Hanói, em 2019). Objetivamente, para os Estados Unidos, o único avanço palpável foi a suspensão, por parte de Pyongyang, dos testes de lançamento de mísseis. A essa altura, contudo, Washington esperava mais. Tampouco houve progresso no conflito entre israelenses e palestinos no Oriente Médio, onde a decisão de Trump de transferir a embaixada americana de Tel Aviv para Jerusalém foi criticada pela maioria dos países-membros da ONU, irritou os palestinos e reduziu a abertura para que os Estados Unidos sejam um mediador válido e permanente nessa questão.

\section{CONSIDERAÇÕES FINAIS}

Em face do novo quadro internacional exposto neste estudo, afirma-se que o governo de Donald Trump surge como uma ruptura do consenso bipartidário longamente construído desde o pós-Segunda Guerra Mundial, apresentando-se como uma característica essencial dessa nova grande estratégia de contornos até agora imprecisos. Ainda em curso e com expectativa de que se possa ter resultados mais concretos colhidos no decorrer dos próximos dois (ou seis) anos, esta mudança não se deu no instante da chegada do presidente ao poder. No final de 2017, por exemplo, na National Security Strategy recém-divulgada, a Coreia do Norte ainda era apontada como rogue state. ${ }^{14} \mathrm{O}$ que se seguiu, após intensa escalada retórica mútua, foi o arrefecimento no tom e as duas cúpulas bilaterais Trump-Kim.

Essa mudança foi se avolumando, conforme Trump enfim impunha seu estilo e conseguia superar (minimizar talvez seja o termo mais adequado) os conflitos entre os diferentes atores que compóem seu gabinete. Em meio à alta rotatividade no primeiro e segundo escalóes, incluindo os departamentos de Estado e de Defesa e o Conselho de Segurança Nacional, e à disputa entre as diferentes tendências político-ideológicas no entorno próximo de Trump, vai ficando mais clara e central a prevalência das preferências do presidente.

Um maior alinhamento entre agentes táo diversos - em visóes de mundo, trajetória, percepçáo do interesse nacional e quanto ao conteúdo e à formulação da política externa e de defesa - deve contribuir para dar a essa política traços mais definidos de uma grande estratégia. Essa maior afinação do trio Trump-Pompeo-Bolton não impedirá, porém, a ocorrência de contradiçóes, recuos e divergências, como visto até então.

14. Sobre o debate a respeito do significado, do uso e da construção do conceito de rogue state, consultar Mizuta (2012). 


\section{REFERÊNCIAS}

BACEVICH, A. J. Saving "America First": what responsible nationalism looks like. Foreign Affairs, Sept./Oct. 2017. Disponível em: <https://www. foreignaffairs.com/articles/2017-08-15/saving-america-first>.

BRANDS, H.; PORTER, P. Why grand strategy still matters in a world of chaos. National Interest, 10 Dec. 2015. Disponível em: <https://nationalinterest.org/ feature/why-grand-strategy-still-matters-world-chaos-14568>.

BRZEZINSKI, Z. Strategic vision: America and the crisis of global power. New York: Basic Books, 2013.

CHINA, Russia sign pact. CNN, 23 Apr. 1997. Disponível em: <https://cnn. it/2GJ5iMt>. Acesso em: jan. 2019.

COX, M. U.S. foreign policy after the Cold War: superpower without a mission? London: Royal Institute of International Affairs, 1995. p. 148.

DAALDER, I. H.; LINDSAY, J. The committee to save the world order: America’s allies must step up as America steps down. Foreign Affairs, Nov./Dec. 2018. Disponível em: <https://www.foreignaffairs.com/articles/2018-09-30/ committee-save-world-order>.

GADDIS, J. L. História da Guerra Fria. Rio de Janeiro: Nova Fronteira, 2006.

A vida de George F. Kennan. São Paulo: Globo Livros, 2014.

GLASSER, S. B. The man who put Andrew Jackson in Trump's oval office. Politico Magazine, 22 Jan. 2018. Disponível em: <https:/www.politico.com/ magazine/story/2018/01/22/andrew-jackson-donald-trump-216493>.

GUIMARÃES, C. Envolvimento e ampliação: a política externa dos Estados Unidos. In: GUIMARÁES, S. P. (Org.). Estados Unidos: visóes brasileiras. Brasília: FUNAG, 2000. p. 9-63.

- A política externa dos Estados Unidos: da primazia ao extremismo. Estudos Avançados, v. 16, n. 46, p. 53-67, 2002.

. Estado de guerra e coesão social na política externa dos Estados Unidos. In: CONFERÊNCIA NACIONAL DE POLÍTICA EXTERNA E POLÍTICA INTERNACIONAL, 1., 2006, Rio de Janeiro. Anais... Brasília: Fundação Alexandre de Gusmão, 2007. p. 181-192.

. Legitimidade e crise na política externa: o governo de George W. Bush. In: CONFERÊNCIA NACIONAL DE POLÍTICA EXTERNA E POLÍTICA INTERNACIONAL, 3., 2008, Rio de Janeiro. Anais... Brasília: Fundação Alexandre de Gusmão, 2008. p. 155-173. 
HAASS, R. N. The age of nonpolarity: what will follow U.S. dominance. Foreign Affairs, v. 87, n. 3, May/June 2008.

IAKOVLEV, N. N. Os homens da Casa Branca: de Truman a Reagan. Lisboa: Avante, 1988.

KAGAN, R. Do paraíso e do poder: os Estados Unidos e a Europa na nova ordem mundial. Rio de Janeiro: Rocco, 2003.

KENNEDY, P. (Ed.). Grand strategies in war and peace. New Haven: Yale University Press, 1991.

KLARE, M. T. Trump's grand strategy. CounterPunch, 26 July 2018. Disponível em: <https://www.counterpunch.org/2018/07/26/trumps-grand-strategy/>.

KUPCHAN, C. A. No one's world: the West, the rising rest, and the coming global turn. New York: Oxford University Press, 2012.

LAYNE, C. From preponderance to offshore balancing: America's future grand strategy. International Security, v. 22, n. 1, p. 8-124, 1997.

LU, D.; YOURISH, K. The turnover at the top of the Trump administration. The New York Times, 18 Sept. 2019. Disponível em: <https://www.nytimes. com/interactive/2018/03/16/us/politics/all-the-major-firings-and-resignationsin-trump-administration.html>.

LUTTWAK, E. Estratégia: a lógica da guerra e da paz. Rio de Janeiro: Biblioteca do Exército Editora, 2009. p. 367.

MARTI, M. E. A China de Deng Xiaoping: o homem que pôs a China na cena do século XXI. Rio de Janeiro: Nova Fronteira, 2007.

MEAD, W. R. The jacksonian tradition: and American foreign policy. The National Interest, n. 58, p. 5-29, 2000.

Donald Trump's jacksonian revolt. Hudson Institute, 13 Nov. 2016.

Disponível em: <https://www.hudson.org/research/13010-donald-trump-sjacksonian-revolt>.

- The jacksonian revolt: American populism and the liberal order. Foreign Affairs, Mar./Apr. 2017. Disponível em: <https://www.foreignaffairs. com/articles/united-states/2017-01-20/jacksonian-revolt>.

MEARSHEIMER, J. J. The tragedy of great power politics. New York: W. W. Norton, 2001.

MEARSHEIMER, J. J.; WALT, S. M. The case for offshore balancing: a superior U.S. grand strategy. Foreign Affairs, July/Aug. 2016. Disponível em: <https://www. foreignaffairs.com/articles/united-states/2016-06-13/case-offshore-balancing>. 
MIZUTA, K. K. O conceito de rogue state e suas implicaçôes na perspectiva da política externa americana. In: ENCONTRO ANUAL DA ASSOCIAÇÃO NACIONAL DE PÓS-GRADUAÇÃO E PESQUISA EM CIÊNCIAS SOCIAIS, 36., 2012, Águas de Lindóia, São Paulo. Papers... São Paulo: ANPOCS, 2012. Disponível em: <https:/www.anpocs.com/index.php/papers36-encontro/gt-2/gt12-2/7977-o-conceito-de-rogue-states-e-suas-implicacoesna-perspectiva-da-politica-externa-americana/file>. Acesso em: set. 2019.

POSEN, B. R. The rise of illiberal hegemony: Trump's surprising grand strategy. Foreign Affairs, Mar./Apr. 2018. Disponível em: <https://www.foreignaffairs. com/articles/2018-02-13/rise-illiberal-hegemony>.

POSEN, B. R.; ROSS, A. L. Competing visions for U.S. grand strategy. International Security, v. 21, n. 3, p. 5-53, 1997.

REICH, R. B. O trabalho das naçóes: preparando-nos para o capitalismo do século XXI. São Paulo: Educator, 1994.

ROTH, P. Os fatos: a autobiografia de um romancista. São Paulo: Companhia das Letras, 2016.

UNITED STATES OF AMERICA. National Security Strategy. Washington: White House, Feb. 2015.

- National Security Strategy of the United States of America. Washington: White House, Dec. 2017.

. Department of Defense. Summary of the 2018 National Defense Strategy of The United States of America. [s.l.]: DOD, 2018. Disponível em: $<$ https://dod.defense.gov/Portals/1/Documents/pubs/2018-National-DefenseStrategy-Summary.pdf $>$.

WRIGHT, T. Trump's foreign policy is no longer unpredictable. Foreign Affairs, 18 Jan. 2019. Disponível em: <https://www.foreignaffairs.com/articles/ world/2019-01-18/trumps-foreign-policy-no-longer-unpredictable>.

ZHONGQI, P. China's changing image of and engagement in world order. In: SUJIAN, G.; BLANCHARD, J.-M. F. (Ed.). "Harmonious world" and China's new foreign policy. New York: Lexington Books, 2010. p. 39-63. 